\title{
Revenue management and its evolution
}

\author{
Ian Yeoman $^{1}$
}

Published online: 30 October 2019

(c) Springer Nature Limited 2019
The purpose of any good standing research journal is to understand the evolution of the past, be a critic of the present and develop new knowledge. However, it is more than theoretical knowledge as Revenue Management and Pricing is fundamentally problem based with a utility expectation. In the last decades, the paradigm of pricing has evolved. In this issue, we explore these dimensions.

No longer is Revenue Management just Revenue Management but a partner to pricing hence the title of this publication, the Journal of Revenue and Pricing Management. We have moved from the philosophy of mass pricing and cost-based pricing to understanding elasticity and creating algorithms to individual pricing. Liozu in his paper on the penetration of the pricing function concludes that findings establish reference measures for future studies and provide benchmark information for pricing executives wishing to establish a pricing function and to justify greater pricing investments. Vinod reports on attribute-based pricing as the new era of retailing in the hospitality industry. This approach to room pricing improves customer satisfaction, since customers can purchase exactly the type of room they want for a memorable stay. Concluding that attribute-based pricing facilitates the management of an infinite number of price points for the infinite options on the price demand curve that can be inventory controlled, thereby generating incremental revenues.

Hotel cancellation policies are an integral part of the hotel revenue management policies and practices and as such, play a crucial role in determining various aspects of the hotel business, including the goal of revenues and profits optimization. According to Riasi and colleagues, hotel cancellation policies in the US have indeed become stricter across the industry. The management of cancellation policies, strategies and operations is stricter with the shortening of the period of cancellation, higher charges and the development

Ian Yeoman

ian.yeoman@vuw.ac.nz

1 Victoria University of Wellington, Wellington, New Zealand of appropriate tools. Like the hotel and airline industry, one of the growth areas of the application of Revenue Management has been the application of Revenue Management in the cruise industry. Sturm's paper challenges existing models of formulation based on booking limits and independence of variables. Right at the heart of Revenue Management in the cruise industry is the cabin capacity allocation problem with the objective maximization of total revenue, resulting from both cabin sales and passengers' onboard spending, generated by a single cruise with only one possible port of embarkation based upon a deterministic demand forecast system. Sturm's finding suggests that in high demand situations, a booking limit policy using the booking limits determined by the proposed model will increase the revenue generated by a cruise. The contribution therefore of the model constitutes an improvement over existing approach.

Schlosser in his paper addresses on how online markets have become highly dynamic and competitive. Many sellers use automated data-driven strategies to estimate demand and to update prices frequently. Schlosser considers the unknown competitors' strategies including reference price effects, and the interaction of data-driven strategies. They propose an automated data-driven strategy for e-commerce sellers to determine real-time price adjustments in competitive settings. The utility benefits of the study find that optimized repricing strategies avoid extreme prices and slightly undercut moderate competitor prices. In addition, restore the price level if needed, and force the competitor to raise the price by using severe price drops.

The airline industry is the heart of Revenue Management. Balaiyan proposes three parametric forecasting models that jointly estimate the volume component and the choice component of airline demand. The models are based on the assumptions of demand volume by considering the average demand of an Origin-Destination (O-D) market, booking curve, seasonality and day-of-the-week indices, and customer behaviour by including the maximum willingness-to-pay of the customer and the choice attributes of the available options. The importance of the model is based on the limitations of discrete-choice models as they usually 
do not consider the demand volume forecast, the seasonality and the customer's maximum willingness-to-pay at the same time. The utility value of the models means that they can be used to forecast bookings for products at a given time interval and also for market-level forecasting. They can be used as an input to price optimization models. Forecast parameters can serve as an input for combined pricing and seat allocation models as well.

Publisher's Note Springer Nature remains neutral with regard to jurisdictional claims in published maps and institutional affiliations. 